\title{
The Chemistry of Dianion-type Zinc Ate Complexes
}

\author{
Masanobu Uchiyama ${ }^{*, \dagger}$ and Yoshinori Kondo*,末 \\ ${ }^{\dagger}$ Institute of Physical and Chemical Research, RIKEN, \\ ${ }^{\ddagger}$ Graduate School of Pharmaceutical Sciences, Tohoku University,
}

Received July 20, 2006

\begin{abstract}
Tools for chemo-, regio- and stereo-selective introduction of various functional groups onto organic molecules are still quite limited in their applicability. Our new approaches to functionalizing organic compounds by means of development of the chemistry of dianion-type zinc ate complexes are described. Reactivity and selectivity of tetra-coordinated dianion-type zincates have been ignored for a long time. Halogen-zinc exchange reaction on aromatic rings and silylzincation of terminal alkynes (and alkenes) using dianion-type zincates followed by electrophilic trapping proved a powerful tool for $\mathrm{C}-\mathrm{C}$ bond formations. The functionalized aromatic or aliphatic zincate intermediate was also found to undergo copper- and palladium-catalyzed $\mathrm{C}-\mathrm{C}$ bond-forming reactions with good yields and high chemoselectivity. On the other hand, a sharp difference in regioselectivity in the epoxide-opening reaction between monoanion-type and dianion-type zincates was disclosed. These results clearly suggest that these dianion-type zincates should be distinguished from ordinary tri-coordinated monoanion-type zincates in terms of structure, reactivity, and selectivity, and hence they would open a new window in synthetic organic chemistry.
\end{abstract}

\section{Introduction}

Organometallic reagents (1) having Lewis acidity often form complexes with an anionic species, such as carboanions, to generate metallic anion complexes defined as ate complexes (2). ${ }^{1}$ Ate complexes have the completely opposite electron configuration from onium complexes (e.g., ammonium salts (4)) and have the characteristic features: 1) mild reactivity, in other words, high stability to various solvents and conditions, because they are formed by electrostatic neutralization from a Lewis acid and base. 2) unique reactivity and selectivity, different from that of the original Lewis acid or base. While most important classes of di-coordinated organozinc derivatives (1: $\mathrm{M}=\mathrm{Zn}(\mathrm{II})$ ) are the organozinc halides (Reformatskytype, symbolized as $\mathrm{RZnX}$ ) and diorganozincs $\left(\mathrm{R}_{2} \mathrm{Zn}\right)$, these organozinc reagents often have poor reactivity without catalysts such as aminoalcohols, transition metals, etc. toward alkylation reaction of the carbonyl compounds and the halogen-metal exchange reaction of alkyl halides. However, triorganozincates $\left(\mathrm{R}_{3} \mathrm{Zn}^{-} \mathrm{Metal}^{+}\right)$are known to effect 1,4 -conjugated addition reaction with $\alpha, \beta$-unsaturated carbonyl compounds, ${ }^{2}$ the metalation reaction of aromatic halides, ${ }^{3}$ aromatic $\mathrm{C}-\mathrm{Hs},{ }^{4}$ or vinyl halides, ${ }^{5}$ and the reduction of various carbonyl compounds ${ }^{6}$ (Figure 1). 3) Flexible design and finetuning of ate complexes are easily done by modifying the ligation environment.

Our group focuses particularly on providing novel approaches to functionalizing organic compounds based on the development of the chemistry of ate complexes. Tools for chemo-, regio- and stereo-selective introduction of various functional groups onto organic molecules are still quite limited in their applicability. One of our approaches capitalizes on tetra-coordinated dianion-type of organozincate reagents (3: $\mathrm{M}=\mathrm{Zn}(\mathrm{II})$ ), which were proposed and developed as a new category of zincates in 1996 by our group and provided novel
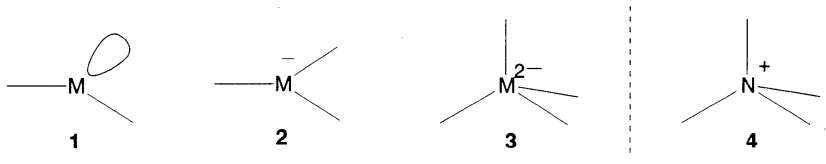

Figure 1

approacles to functionalizing onganic compounds. This account describes the design, development, reactivity of dianion-type zincates, and its practical application to organic synthesis.

\section{Design, Structure, and Reactivity of Dianion-type Ate Complexes}

\subsection{Design of Dianion-type Zincates}

Figure 2 shows the basic scheme for the dianion-type zincates that we designed as a new type of zincate in $1996 .^{7}$ Normal trialkylzincates can be prepared from dialkylzinc having Lewis acidity and an alkyl anion possessing Lewis basicity. The outer shell of the zinc atom in a trialkylzincate is filled with 16 electrons, and there is a vacant orbital for an additional ligand to coordinate, forming a favorable 18-electron-state. Therefore, lithium trialkylzincate may form further complexes with an anionic species, such as MeLi, $\mathrm{LiCN}$, LiSCN, to generate tetracoordinated organozinc derivatives. However, at that time, the nature of the tetraalkylzincates had not been well studied.

First, the preparation of newly designed methyl zincates was investigated and the ${ }^{1} \mathrm{H}$ NMR spectra of the zincates were obtained for the preliminary estimation of the component of the zincate solution. Dilithium tetramethylzincate was prepared by the reaction of zinc chloride with 4 equiv of MeLi in THF using the previously reported modified procedure. ${ }^{8}$ The methyl signal of $\mathrm{Me}_{4} \mathrm{ZnLi}_{2}$ in $\mathrm{THF}(-1.44 \mathrm{ppm})$ 


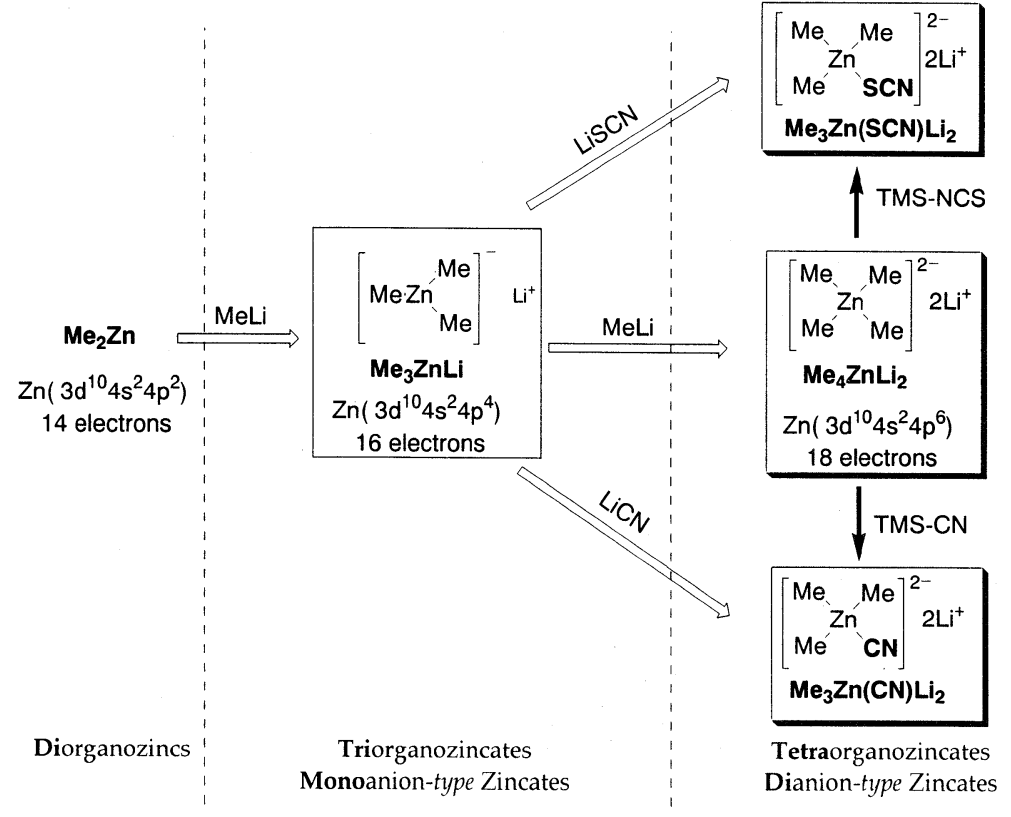

Figure 2. Design of new ate complexes of organozinc derivatives.

are tetracoordinated, dianionic zinc structures. These results indicate that the different zincate species are formed, and we are intrigued by the enhanced anionic character of these newly designed zincates compared to $\mathrm{Me}_{3} \mathrm{ZnLi}$, to investigate the following reactions.

\subsection{Halogen-Metal Exchange Reactivi- ties of Dianion-type Zincates}

Since the pioneering work by Gilman and Wittig, ${ }^{12}$ the halogen-metal interconversion reaction with the use of alkyllithiums or Grignard reagents has been considered an intriguing approach to $\mathrm{C}-\mathrm{C}, \mathrm{C}-\mathrm{X}$, and $\mathrm{C}$-metal bond formation on aromatic rings in organic synthesis, because of the easy procedure, high reactivity, and high regio-controllability (regioisomeric products are not formed). However, the application of this reaction to the elaboration of complex organic structures is generally limited by low functional group tolerance, significant formation of by-products, and severe restric-

was observed as a sharp singlet in the middle between the signals of $\mathrm{Me}_{3} \mathrm{ZnLi}(-1.08 \mathrm{ppm})$ and $\mathrm{MeLi}(-1.96 \mathrm{ppm})$. Measurement at $-78{ }^{\circ} \mathrm{C}$ gave very similar results but with a slight high-field shift of each signal. The addition of one more equivalent of $\mathrm{MeLi}$ to the $\mathrm{Me}_{4} \mathrm{ZnLi}_{2}$ solution showed a broad singlet signal at $-1.49 \mathrm{ppm}$ at $-20{ }^{\circ} \mathrm{C}$ which separated at $-78{ }^{\circ} \mathrm{C}$ into two signals corresponding to the signal of MeLi and that of $\mathrm{Me}_{4} \mathrm{ZnLi}_{2}$. The high-field shift from the value of $\mathrm{Me}_{3} \mathrm{ZnLi}$ is considered to indicate the more anionic character of the zincates. Indeed, there are some reports of tetraalkylzincates, ${ }^{9}$ and $\mathrm{X}$-ray studies of the zincates which have disclosed that the crystal structures of the tetraalkylzincates are in a tetrahedral $\left(\mathrm{sp}^{3}\right.$ like) dianionic arrangement, while those of the trialkylzincates are in a trigonal $\left(\mathrm{sp}^{2}\right.$ like) monoanionic arrangement about the $\mathrm{Zn}$ atom. ${ }^{10}$

The addition of 1 equiv of $\mathrm{Me}_{3} \mathrm{SiCN}$ or $\mathrm{Me}_{3} \mathrm{SiNCS}$ to the $\mathrm{Me}_{4} \mathrm{ZnLi}_{2}$ solution should give the zincates with a methyl group replacement by the $\mathrm{CN}$ or SCN ligand. $\mathrm{Me}_{3} \mathrm{Zn}(\mathrm{CN}) \mathrm{Li}_{2}$ and $\mathrm{Me}_{3} \mathrm{Zn}(\mathrm{SCN}) \mathrm{Li}_{2}$, and their methyl signals were observed as sharp singlets $\left(-1.20 \mathrm{ppm}\right.$ for $\mathrm{Me}_{3} \mathrm{Zn}(\mathrm{CN}) \mathrm{Li}_{2}$ and -1.23 ppm for $\left.\mathrm{Me}_{3} \mathrm{Zn}(\mathrm{SCN}) \mathrm{Li}_{2}\right)$. At the same time, the signal of the newly generated tetramethylsilane in the mixture was also observed at $0.00 \mathrm{ppm}$ together with the disappearance of the signal of $\mathrm{Me}_{3} \mathrm{SiCN}(0.38 \mathrm{ppm})$ or $\mathrm{Me}_{3} \mathrm{SiNCS}(0.40 \mathrm{ppm})$. A high-field shift from the value of $\mathrm{Me}_{3} \mathrm{Zn}(\mathrm{CN}) \mathrm{Li}_{2}$ was considered to show the more anionic character of each dianiontype zincate.

In addition, to obtain additional information about the structures of the newly designed dianion-type zincates, we measured Raman, Extended X-ray Absorption Fine Structure (EXAFS), and in situ FTIR spectra of $\mathrm{Me}_{3} \mathrm{Zn}(\mathrm{SCN}) \mathrm{Li}_{2}$, $\mathrm{Me}_{3} \mathrm{Zn}(\mathrm{CN}) \mathrm{Li}_{2}$, and related monoanion-type zincates. ${ }^{11}$ Space limitation does not permit us to deal with more details of these spectroscopic studies, but the combination of the results obtained from ${ }^{1} \mathrm{H}$ NMR, Raman, Extended X-ray Absorption Fine Structure (EXAFS), and in situ FTIR spectroscopies of cyano- and thiocyano-substituted new zincates strongly support that $\mathrm{Me}_{3} \mathrm{Zn}(\mathrm{CN}) \mathrm{Li}_{2}$ and $\mathrm{Me}_{3} \mathrm{Zn}(\mathrm{SCN}) \mathrm{Li}_{2}$ tions regarding reaction conditions, particularly the extremely low temperature and strict exclusion of acidic protons typically required for such reactions. These limitations arise because general organometallics have not only halogen-metal exchange ability, but also high nucleophilicity and basicity, and these features have been regarded as difficult or impossible to separate. Thus, the development of a protectinggroup-free halogen-metal exchange reaction with high functional group- and acidic proton compatibility remains a tremendous challenge in organic and organometallic chemistry.

In 1994, Kondo reported the iodine-zinc exchange reaction between iodobenzenes and trimethylzincate $\left(\mathrm{Me}_{3} \mathrm{ZnLi}\right)$, which opens a new window in chemoselective halogen-zinc exchange chemistry on aromatic rings. ${ }^{3 \mathrm{a}}$ The reaction possesses a number of attractive features as a synthetic reaction. For instance, (1) it is compatible with a wide variety of functional groups, such as esters, amides, and even nitro group. (2) It proceeds smoothly under mild conditions (extremely low temperature is not required), and (3) the resultant zincate intermediates generated by the exchange reaction of functionalized iodobenzenes with $\mathrm{Me}_{3} \mathrm{ZnLi}$ can be successfully used as aryl anion equivalents in $\mathrm{C}-\mathrm{C}$ bond-forming and transmetalation reactions.

However, aromatic bromides were unreactive in this interconversion process. Since the newly designed dianion-type zincates are considered to have more anionic character based on our preliminary ${ }^{1} \mathrm{H}$ NMR study, the bromine-zinc exchange reaction of bromobenzene was then investigated (Table 1). The reaction was carried out and the resulting metal species was trapped with benzaldehyde. Although the favorable reaction temperature depends to some degree on the zincates, the exchange reaction using dianion-type zincates proceeded smoothly at $0{ }^{\circ} \mathrm{C}$ or $\mathrm{rt}$ to give the desired benzhydrol in quantitative yields as expected (Entries 3-5). Under similar reaction conditions, the reaction with $\mathrm{Me}_{3} \mathrm{ZnLi}$ did not proceed at all (Entry 2) and MeLi was also found inactive under the similar conditions. This rules out the promotion of this poly- 
Table 1. Halogen-zinc exchange reaction on benzene ring.

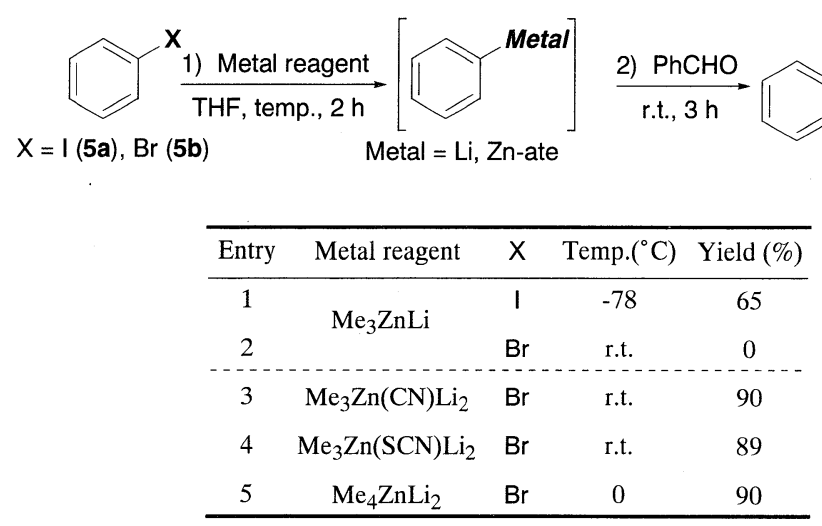

merization by free MeLi or $\mathrm{Me}_{3} \mathrm{ZnLi}$.

Synthetic applications of organotellurium compounds have increased in recent years. ${ }^{13}$ Among their many synthetic uses, transmetalation reaction with organolithium or organocuprate reagents is considered to be important for $\mathrm{C}-\mathrm{C}$ bond formation. ${ }^{14}$ In connection with our studies on pyridinylmetal derivatives, ${ }^{15}$ we investigated the preparation of 2-pyridinyltellurium derivatives. After extensive experimentation, we found that butyl 2-pyridyltelluride (7) was easily prepared by the nucleophilic substitution of 2-bromopyridine and 2-chloropyridine with lithium butanetelluroate to give the telluride (7) in $70 \%$ and $61 \%$ yields, respectively, ${ }^{16}$ although 2-halopyridines were generally difficult to prepare chemo- and regioselectively by electrophilic substitution with iodine or bromine.

The tellurium-zinc exchange reaction of 2-pyridinyltellurium compounds using various zincates was next investigated (Table 2).

Table 2. Tellurium-zinc exchange reaction.

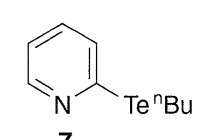

1) Zincate
THF, Conditions
2) $\mathrm{PhCHO}, \mathrm{rt}, 3 \mathrm{~h}$

$$
7
$$

\begin{tabular}{ccccc}
\hline Entry & Zincate & ${ }^{1} \mathrm{H}-\mathrm{NMR} \delta_{\mathrm{Me}}$ & Conditions & Yield (\%) \\
\hline 1 & $\mathrm{Me}_{3} \mathrm{ZnLi}$ & $-1.08 \mathrm{ppm}$ & $\mathrm{rt}, 18 \mathrm{~h}$ & 0 \\
2 & $\mathrm{Me}_{3} \mathrm{Zn}(\mathrm{CN}) \mathrm{Li}_{2}$ & $-1.20 \mathrm{ppm}$ & $\mathrm{rt}, 2 \mathrm{~h}$ & 63 \\
3 & $\mathrm{Me}_{3} \mathrm{Zn}(\mathrm{SCN}) \mathrm{Li}_{2}$ & $-1.23 \mathrm{ppm}$ & $\mathrm{rt}, 2 \mathrm{~h}$ & 58 \\
4 & $\mathrm{Me}_{4} \mathrm{ZnLi}_{2}$ & $-1.44 \mathrm{ppm}$ & $0^{\circ} \mathrm{C}, 2 \mathrm{~h}$ & 81 \\
\hline
\end{tabular}

Butyl 2-pyridyltelluride (7) was treated with $\mathrm{Me}_{4} \mathrm{ZnLi}_{2}$ in THF at $0{ }^{\circ} \mathrm{C}$ in $2 \mathrm{~h}$ and then with benzaldehyde to give phenyl(2-pyridinyl)methanol (8) in $81 \%$ yield (Entry 4), while the reaction with $\mathrm{Me}_{3} \mathrm{ZnLi}$ did not proceed at all even under harsher conditions ( $\mathrm{rt}, 18 \mathrm{~h}$ ) (Entry 1). The modified zincates, $\mathrm{Me}_{3} \mathrm{Zn}(\mathrm{CN}) \mathrm{Li}_{2}$ and $\mathrm{Me}_{3} \mathrm{Zn}(\mathrm{SCN}) \mathrm{Li}_{2}$, also showed high reactivity toward the tellurium-zinc exchange reaction although it required higher temperature and the desired product (8) was obtained in 63\% and 58\% yields, respectively (Entries 2 and 3 ). From these results, the tellurium-zinc exchange reaction using dianion-type zincates is considered to proceed smoothly to form the dianion-type 2-pyridinyl-zincates.

All these results make it clear that the dianion-type zin- cates have higher reactivity toward the halogen (or tellurium)-zinc exchange reaction than the normally tricoordinated monoanion-type zincate, $\mathrm{R}_{3} \mathrm{ZnLi}$. These results also imply the difference in reactivity between the intermediary aromatic zincates arising from dianion-type zincates and those from $\mathrm{R}_{3} \mathrm{ZnLi}$.

\subsection{Reactivity and Selectivity of The Inter- mediary Aromatic Zincates Generated by Halogen-Zinc Exchange Reaction Using Dianion-type Zincate}

Changes in the number of ligands on $\mathrm{Zn}$ could affect reactivities and selectivities of the intermediary aromatic zincates in various reactions. We shall introduce some typical examples in this section.

\section{Intramolecular Carbozincation Reaction}

In the intramolecular carbozincation reaction of allyl 2-iodophenyl ether (9), the number of ligands on the zincate is critical for achievement of the reaction. When 9 was treated with $\mathrm{Me}_{3} \mathrm{ZnLi}$, the iodine-zinc exchange reaction proceeded smoothly but no intramolecular carbometalation reaction was observed to get dehalogenation product (11) in quantitative yield (Scheme 1, top). On the other hand, the reaction of 9 with $\mathrm{Me}_{4} \mathrm{ZnLi}_{2}$ followed by hydrolysis gave 3-methyl-2,3dihydrobenzo $[b]$ furan $(14)$ in $42 \%$ yield, which probably results from the intramolecular carbozincation reaction of arylzincate (12) (Scheme 1, bottom). However, during the reaction of 9 with $\mathrm{Me}_{3} \mathrm{Zn}(\mathrm{CN}) \mathrm{Li}_{2}, \mathrm{Me}_{3} \mathrm{Zn}(\mathrm{SCN}) \mathrm{Li}_{2}$, and $\mathrm{Me}_{2} \mathrm{Cu}(\mathrm{CN}) \mathrm{Li}_{2}$, the intramolecular carbozincation reaction did not proceed at all.

This method was also applicable to a synthesis of substituted indoline derivatives (Scheme 2).

\section{Intramolecular Epoxide Ring Opening Reaction}

Epoxide (Oxirane) is among the most important functional groups in organic chemistry and has a highly sterically strained unique structure. Recently, there has been considerable progress in ring formation by intramolecular epoxide ring-opening reactions. Various epoxides including enantiomerically pure epoxides have been easily obtained in recent years. Therefore, such regioselectivity is getting more and more important for organic synthesis.

Our next interest was then focused on the intramolecular epoxide ring-opening reaction of epoxide (15) using the zincates as metalating agents (Table 3 ). Based on Baldwin's rules, ${ }^{17} 3$-membered rings including epoxides generally prefer the exo mode of attack, while several exceptional reactions were also reported. ${ }^{18}$ In fact, the reaction with $\mathrm{Me}_{3} \mathrm{ZnLi}$ gave an anti-Baldwin's rule product, endo-cyclized 1,2,3,4-tetrahydroquinoline derivative (17), as the major product, while the reaction with $\mathrm{Me}_{3} \mathrm{Zn}(\mathrm{SCN}) \mathrm{Li}_{2}$ gave the exo-cyclized indoline derivative (16). Especially, the reaction with $\mathrm{Me}_{3} \mathrm{ZnLi}$ and the reaction with $\mathrm{Me}_{3} \mathrm{Zn}(\mathrm{SCN}) \mathrm{Li}_{2}$ showed almost perfect reverse regioselectivity (Entries 1 and 4). The more interesting point is that all dianion-type zincates showed the almost completely opposite regioselectivity from $\mathrm{Me}_{3} \mathrm{ZnLi}$ for the ring-opening reaction. This method was considered to be applicable for the chiral synthesis of 3-indolinemethanol derivatives and 3hydroxytetrahydroquinoline derivatives, key precursors for the synthesis of CC-1065/duocarmycin pharmacophore known as potent antitumor antibiotics (Figure 3). ${ }^{19}$ 
Scheme 1. Intramolecular carbozincation (1).

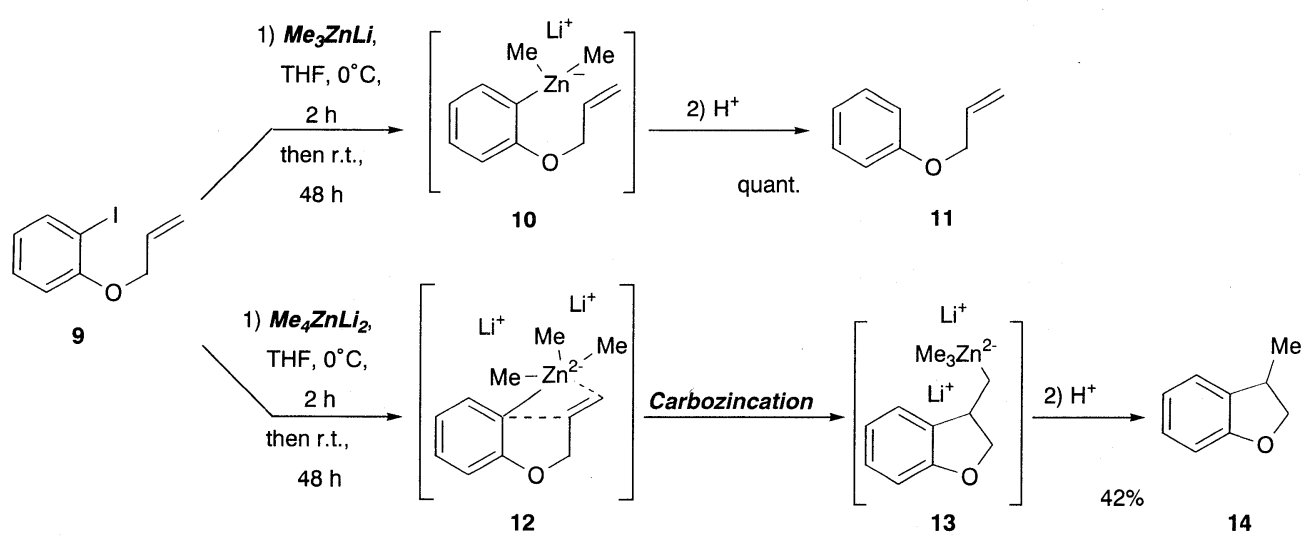

Scheme 2. Intramolecular carbozincation (2).

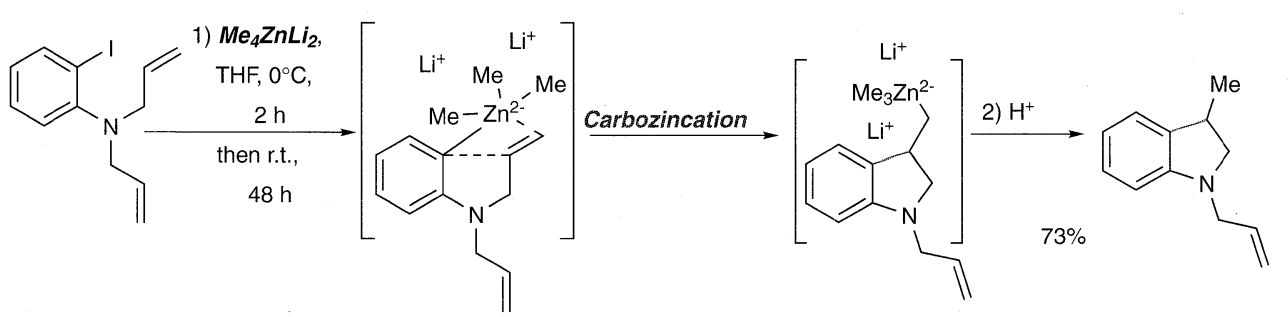

Table 3. Intramolecular epoxide opening reaction.

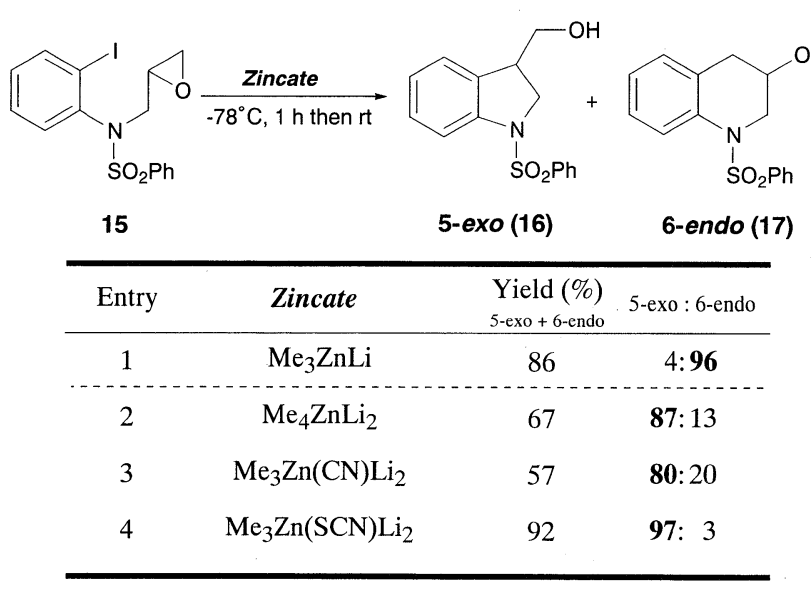<smiles></smiles>

(+)-CC-1065

\section{Intermolecular Silylation of Functionalized Terminal C-C Unsaturated Bonds using Dianion-type Silylzincates}

\subsection{Silylzincation of Functionalized Terminal Alkynes}

Carbon-carbon double bonds are key structural features of organic molecules, and control of $\mathrm{C}=\mathrm{C}$ bond geometry has been one of the central issues in organic synthesis. ${ }^{20}$ The intermolecular silylmetalation of alkynes constitutes an excellent method for construction of multisubstituted olefins. However, controlling the chemo- and regioselectivity in the silylmetalation of unsymmetrical alkynes remains an important challenge. In particular, very limited success has been reported in regioselective silylmetalation to give branched vinylsilanes from terminal alkynes. ${ }^{21}$ We describe here a newly designed dianion-type silylzincate complex that pro-

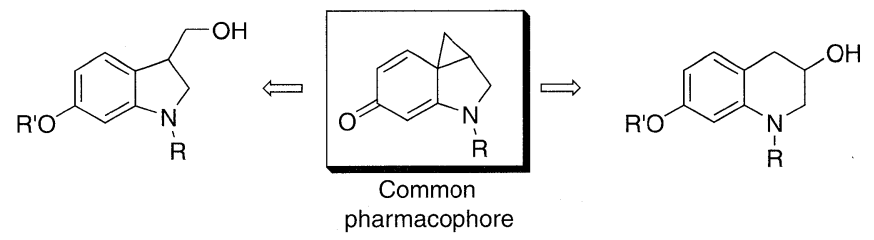

Figure 3 
Table 4. Silylzincation of 1-octyne (18).

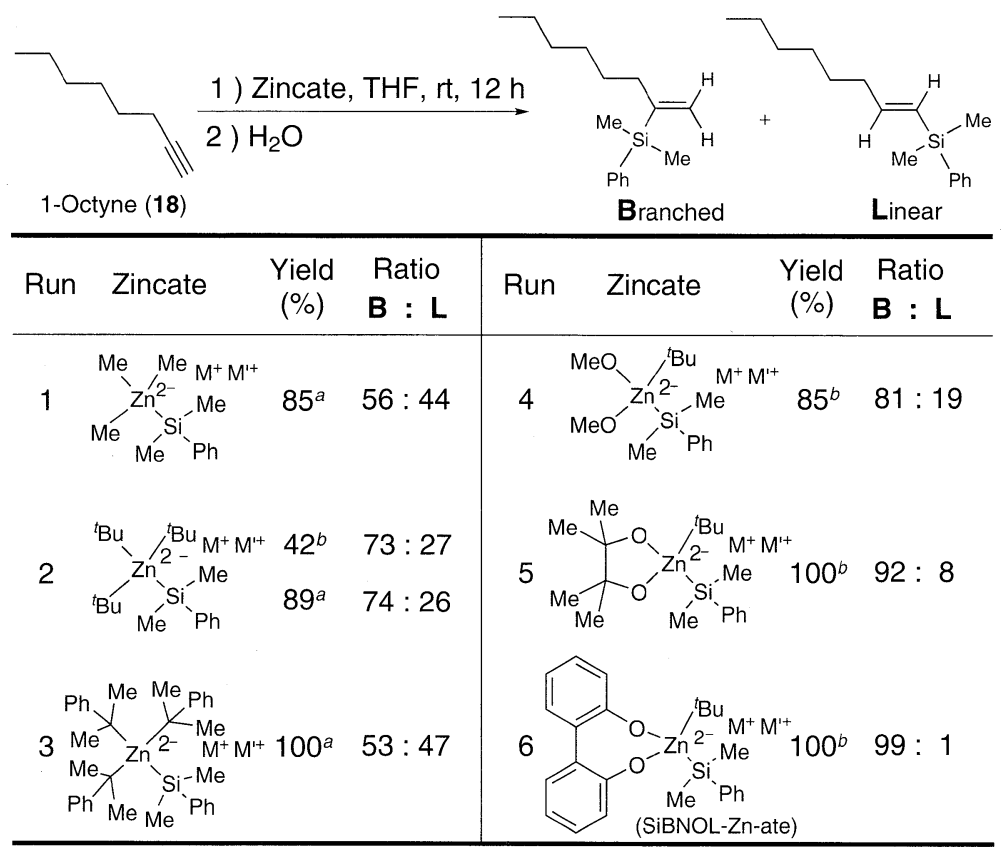

${ }^{a}$ Counter cations $\left(\mathrm{M}^{+}, \mathrm{M}^{+}\right)$were $2 \mathrm{Li}^{+} .{ }^{b}$ Counter cations were $\mathrm{Li}^{+}, \mathrm{Mg}^{+} \mathrm{Cl}$ or $2 \mathrm{Mg}^{+} \mathrm{Cl}$.

Table 5. Silylzincation of various functionalized terminal acetylenes.

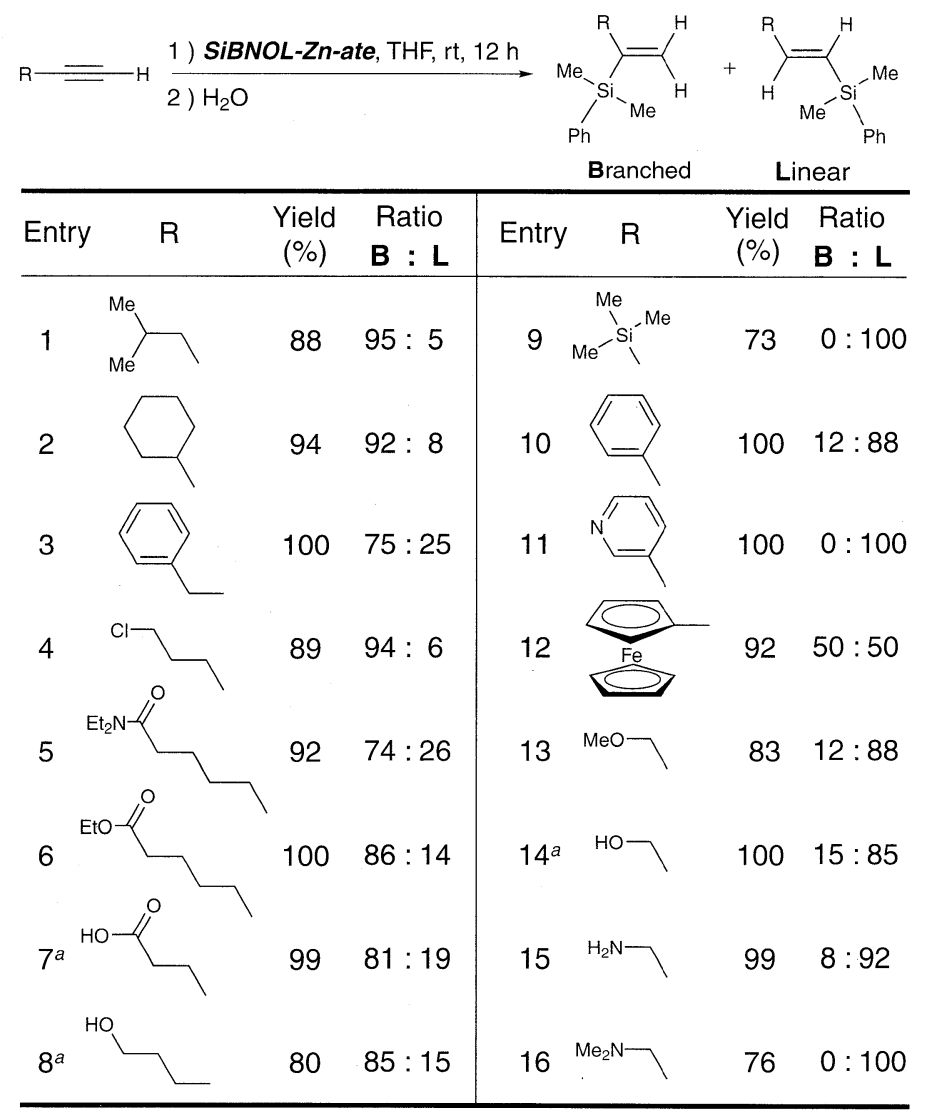

$a$ The reaction was carried out using SiBNOL-Zn-ate (2.2 eq).

motes highly chemo- and regioselective silylzincation of unfunctionalized and functionalized terminal alkynes without any transition metal catalyst. ${ }^{22}$

Several attempts to use the monoanion-type silylzincates proved unsuccessful in terms of the reactivity (yields) and (branch-)selectivity. On the other hand, 1 eq of dianion-type silylzincates turned out to promote the silylzincation of 18, without any catalysts, in good to excellent yields at room temperature. Various dianion-type zincates were examined (Table 4), and a combination of biphenoxo and ${ }^{t} \mathrm{Bu}$ (SiBNOL-Zn-ate) (Run 6), gave the best result in terms of yield and branch-selectivity. It is interesting to note that the use of ${ }^{t} \mathrm{BuMgCl}$ instead of ${ }^{t} \mathrm{BuLi}$, is critical to achieve good chemical yield and high branch-selectivity.

This silylzincation reaction to afford various vinylsilanes turned out to be synthetically complementary to the previously reported methods in that we can use various functionalized alkynes as substrates for the first time (Table 5). Not only alkyl groups, but also a variety of polar functional groups including an aliphatic chloride, amide, ester, and TMS (Entries 4-7, 9, 13, 16) are tolerated in the reaction. Substrates containing an $\mathrm{O}-\mathrm{H}$ or an $\mathrm{N}-\mathrm{H}$ moiety, such as aliphatic alcohols, carboxylic acid, and amine, can also be utilized by employing SiBNOL-Zn-ate, and no self-condensation was observed (Entries 7, 8, $14,15)$. A $\pi$-deficient hetero-aromatic moiety also caused no problem (Entry 11).

In addition, the reaction possesses a number of attractive features as a synthetic reaction. For instance, it can be carried out as a transition metal-free reaction and therefore the terminal alkyne specificity of the present reaction is very high, i.e., other unsaturated bonds, such as internal alkyne, alkene, and diene, are left intact (Figure 4).

The resultant vinylzincate can be a potent intermediate for regio-controlled trisubstituted olefins, which provide basic architecture for functionalized materials (Figure 5). For instance, the intermediate vinylzincate, generated by the silylzincation of 1-octyne using SiBNOL-Zn-ate, was treated with $\mathrm{D}_{2} \mathrm{O}$ or allyl bromide to give the corresponding deuterated or allylated olefins in $90 \%$ and $94 \%$ yields, respectively. The vinylzincate intermediate also undergoes copper- and palladium-catalyzed $\mathrm{C}-\mathrm{C}$ bondforming reactions in high yields and with high regioselectivities.

\subsection{Silylzincation of Functionalized Ter- minal Alkynes}

Allylsilanes are important intermediates for carbon-carbon and carbon-heteroatom bond formation in organic synthesis because of their easy handling, unique reactivities, and high regio-controllability. ${ }^{23}$ Methods currently available for their synthesis include transition metal-catalyzed silylmetalation of 1,3-dienes or allenes and Wittig reactions. ${ }^{24}$ Unfortunately, 


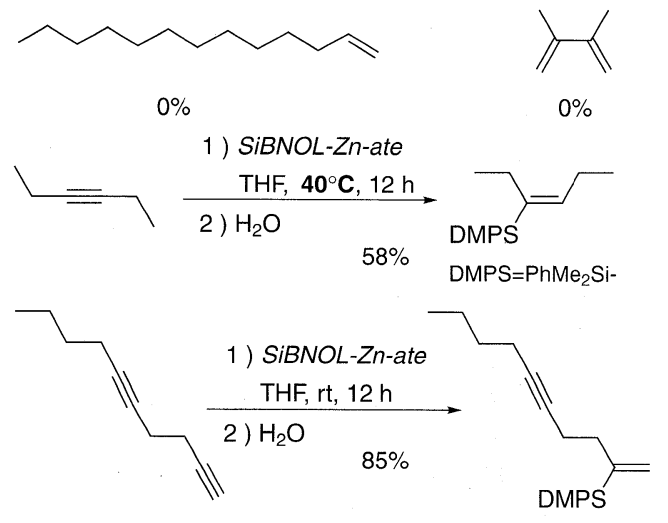

Figure 4. Chemoselectivity of this silylzincation. however, many of these reactions have significant disadvantages: low generality, low chemoselectivity, the requirement for tedious multi-step synthesis of the precursor, and so on. This section presents the first $\mathrm{Cp}_{2} \mathrm{TiCl}_{2}$-catalyzed regio-/ chemoselective silylmetalation reaction between a readily available terminal alkene and a newly developed silylzincate (SiSiNOL-Zn-ate) to give a variety of $\gamma$-substituted allylsilanes (Table 6, Entry 7). ${ }^{25}$

This method possesses a number of attractive features as a synthetic reaction (Table 7 and Figure 6). For instance, (1) this reaction is the first example of an efficient one-step synthesis of $\gamma$-substituted allylsilanes, (2) we can use various functionalized alkenes as substrates, (3) it can be carried out smoothly in the presence of $5 \mathrm{~mol} \% \mathrm{Cp}_{2} \mathrm{TiCl}_{2}$, (4) the terminal alkene specificity of the present reaction is very high, i.e.,

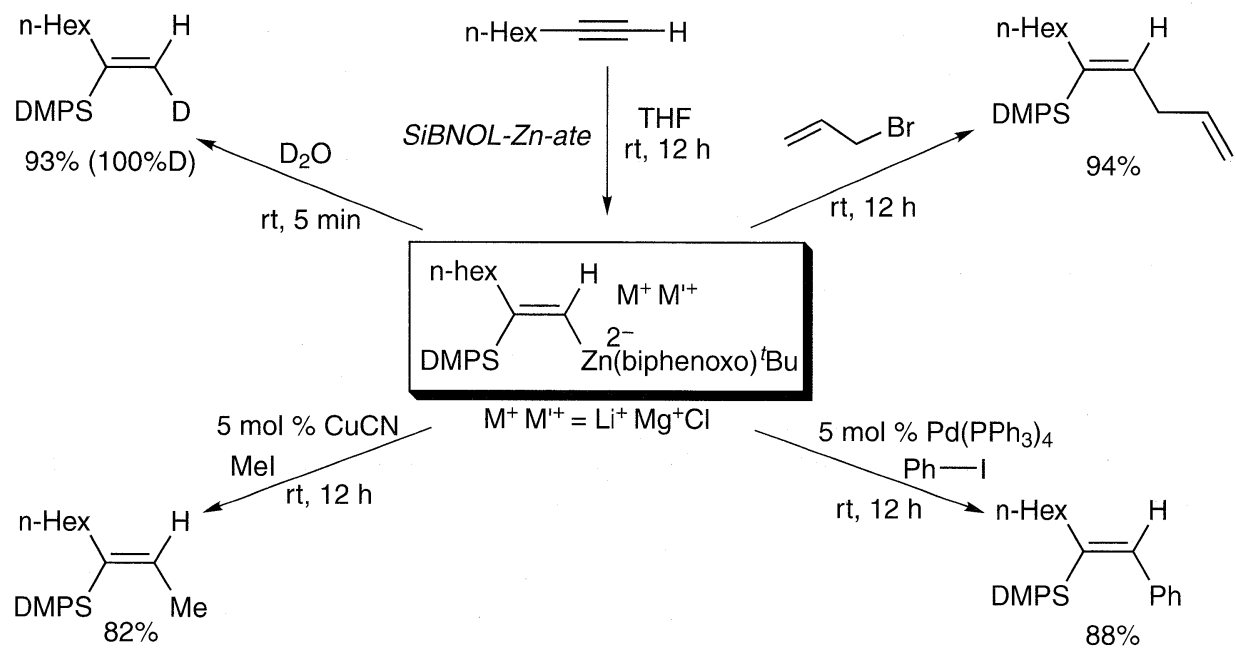

Figure 5. Electrophilic trapping of the intermediate generated in situ by silylzincation of 1-octyne (18) Using SiBNOL-Zn-ate.

Table 6. Screening of zincates for $\mathrm{Cp}_{2} \mathrm{TiCl}_{2}$-Catalyzed silylation of 1-heptene (19).

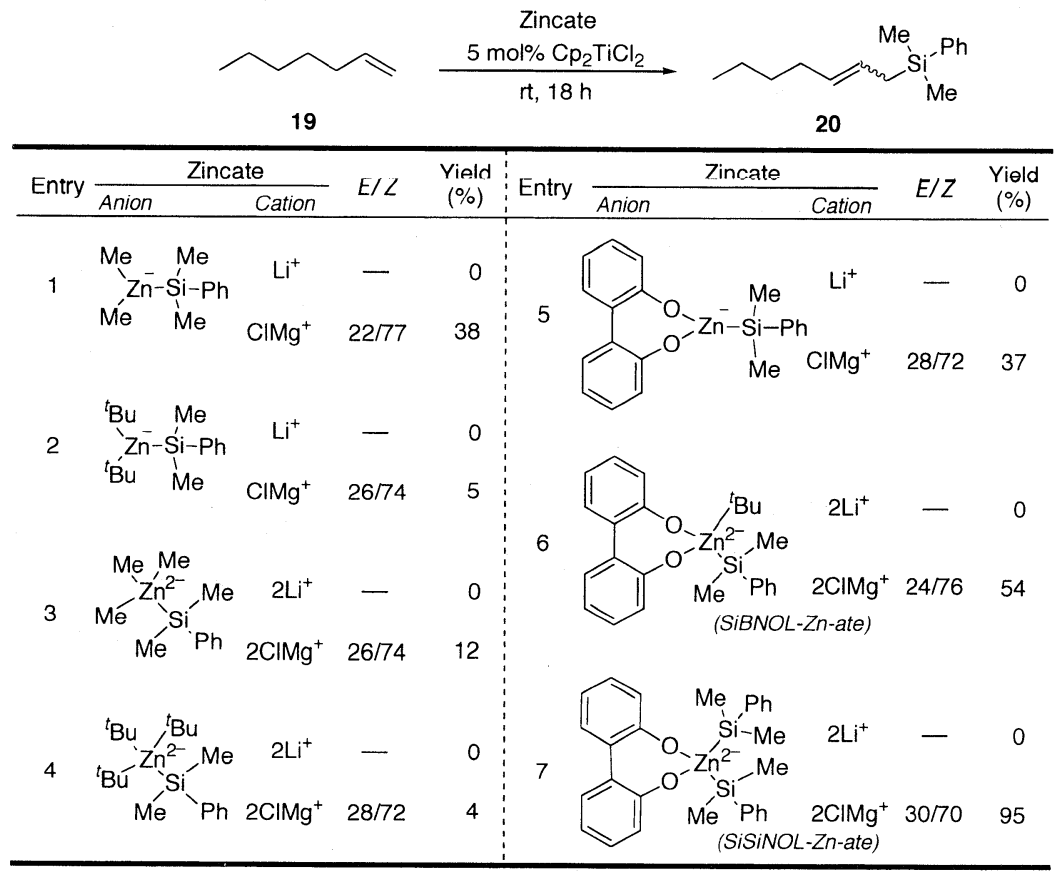


Table 7. Silylation of various functionalized terminal alkenes.

$$
\begin{aligned}
& \mathrm{R} \curvearrowright \frac{5 \mathrm{~mol} \% \mathrm{Cp}_{2} \mathrm{TiCl}_{2}, \mathrm{SiSiNOL-Zn-ate}}{\mathrm{THF}, \mathrm{rt}, 18 \mathrm{~h}} \mathrm{R} \underset{\mathrm{Me}}{\mathrm{M}} \mathrm{Si}^{-\mathrm{Ph}} \\
& 21
\end{aligned}
$$

\begin{tabular}{|c|c|c|c|c|c|c|c|}
\hline Entry & $R$ & $E / Z$ & $\begin{array}{c}\text { Yield } \\
(\%)\end{array}$ & Entry & $\mathrm{R}$ & $E / Z$ & $\begin{array}{c}\text { Yield } \\
(\%)\end{array}$ \\
\hline 1 & & $24 / 76$ & 95 & 8 & & $24 / 76$ & 95 \\
\hline 2 & & $28 / 72$ & 92 & 9 & & $27 / 73$ & 79 \\
\hline $3^{a}$ & & $29 / 71$ & 94 & 10 & & $23 / 77$ & 80 \\
\hline 4 & & $26 / 74$ & 88 & 11 & & N.D. & 84 \\
\hline 5 & & $21 / 79$ & 75 & $12^{c}$ & & $49 / 51$ & $47^{d}$ \\
\hline $6^{b}$ & & $26 / 74$ & 55 & 13 & & $26 / 74$ & $71^{e}$ \\
\hline $7^{b}$ & & $24 / 76$ & 100 & 14 & & $21 / 79$ & $81^{f}$ \\
\hline
\end{tabular}

${ }^{a}$ The reaction was carried out under reflux. ${ }^{b} 3$ eq of zincate was used. ${ }^{c}$ The reaction was carried out at $45^{\circ} \mathrm{C}$

${ }^{d}$ Vinylsilane was isolated in $18 \%$ yield $(E / Z=64 / 36) .{ }^{e}$ Vinylsilane was isolated in $8 \%$ yield $(E / Z=58 / 42)$.

${ }^{f}$ Vinylsilane was isolated in $19 \%$ yield $(E / Z=50 / 50)$.

other unsaturated bonds (such as internal alkene) remain intact, and (5) no isomerization of the $\mathrm{C}-\mathrm{C}$ double bond of the resultant allylsilanes was observed. Such isomerization often leads to synthetic problems in $\mathrm{Ru}-$ and $\mathrm{Pd}$-catalyzed reactions. ${ }^{26}$

The resultant $\gamma$-substituted allylsilanes can be utilized as allylating agents in the presence of Lewis acids with high chemo- and regioselectivity (Figure 7). The allylsilanes also react with $\mathrm{mCPBA}$ or $\mathrm{BH}_{3}$. THF to give the corresponding oxidized products in moderate to high yields with high regioselectivities. These multi-functionalities can easily be further transformed in various ways, so that the synthetic value of ?-substituted allylsilanes would be greatly extended by the present approach.

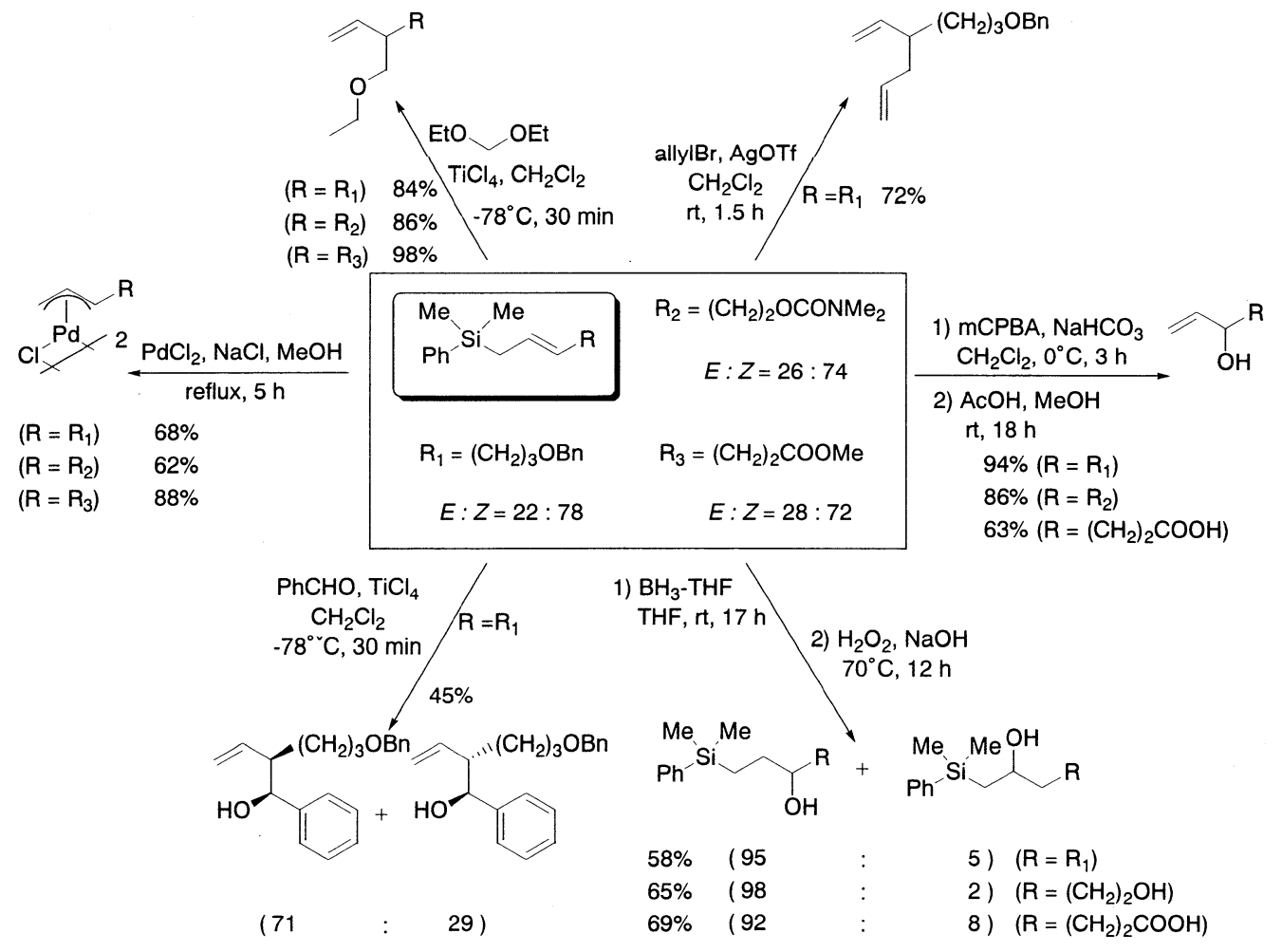

Figure 7. Reactivity of the functionalized allylsilanes. 


\section{Design and Application of Bulky Zincate Possessing Little Basicity using Dianion-type Silylzincates}

Alkyllithiums or Grignard reagents are too highly reactive to co-exist with various electrophilic functional groups. Moreover, severe restrictions, particularly the extremely low temperature and exclusion of acidic protons, are typically required for such reactions. These limitations arise because general organometallics have halogen-metal exchange ability, nucleophilicity, and basicity, and these features have been regarded as difficult or impossible to separate. Thus, the development of a versatile halogen-metal exchange or nucleophilic reagent with little basicity remains a tremendous challenge in organic and organometallic chemistry. We would like to show here two our recent successful examples. The first topic is anionic polymerization in protic solvents, and the second topic treats the development of a new halogen-metal exchange reaction reagent with low basicity and nucleophilicity.

\subsection{A New Chemoselective Anionic Polymerization Method in Aqueous Media}

Anionic polymerization reaction is among the most important methodologies in synthetic polymer chemistry. ${ }^{27}$ Alkyllithiums $^{28}$ and Grignard reagents ${ }^{29}$ have been widely used as powerful anionic initiators for prototypic anionic polymerization reactions such as that of styrene. Despite the synthetic potential of anionic polymerization, its use has been limited to less functionalized monomers. With highly functionalized monomers, undesirable side reactions, termination, or migration reactions can occur, because the initiators or the intermediary metal species are too reactive to co-exist with various electrophilic functional groups such as carbonyl groups (amides, esters, etc.), acidic hydrogen $(\mathrm{NH}$, $\mathrm{OH}$, etc.), and so on. In addition, the usual requirement of strict exclusion of moisture has limited the utility of the anionic polymerization, especially at the industrial level. Thus, a new and practical anionic polymerization method with high functional group compatibility is highly desirable.

Poly ( $N$-isopropylacrylamide) (PNIPAm, Scheme 3), an interesting new polymer, exhibits unique temperature-sensitive properties. ${ }^{30}$ It has been applied in various ways in organic chemistry, ${ }^{31}$ biotechnology, ${ }^{32}$ and material sciences. ${ }^{33}$

Scheme 3. Anionic porimerization of NIPAnn initialed by ${ }^{\prime} \mathrm{Bu}_{4} \mathrm{ZnLi}_{2}$.

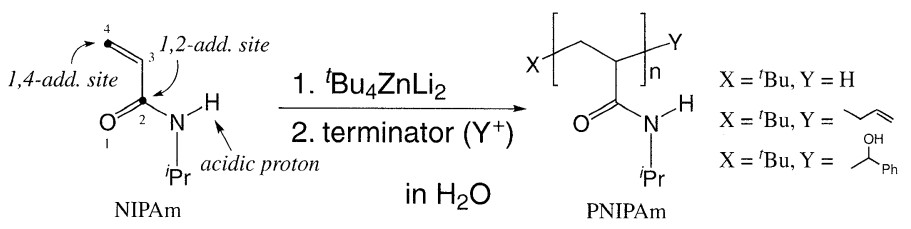

However, since the multi-functionalized monomer, NIPAm, possesses an acidic amide-NH hydrogen and a conjugated carbonyl moiety which can work as a 1,2-addition site, in addition to the desired 1,4-addition site, the polymerization of unprotected NIPAm has been reported only in a radical fashion. ${ }^{34}$ From the viewpoints of flexibility and applicability for functionalization of PNIPAm, the development of chemo-selective anionic polymerization would be extremely useful.
We developed a new organozincate-mediated anionic polymerization (ZAP) using ${ }^{t} \mathrm{Bu}_{4} \mathrm{ZnLi}_{2}$ as an initiator (Scheme 3). Several features of this new ZAP protocol are noteworthy. First, this anionic polymerization has high compatibility with protic solvents, which significantly accelerate the reactions (Figure 8). When a protic polar solvent such as $\mathrm{MeOH}$ or $\mathrm{H}_{2} \mathrm{O}$ was used, the polymerization reaction was dramatically accelerated as compared with that in an aprotic, less polar solvent, THF. In $\mathrm{H}_{2} \mathrm{O}$, the yield was increased and reached the maximum $(92 \%)$, within $1 \mathrm{~h}$. The finding that a polar solvent accelerated the polymerization reaction is characteristic of ionic polymerization. This method is free from any requirement for the protection of acidic protons or strictly anhydrous reaction conditions.

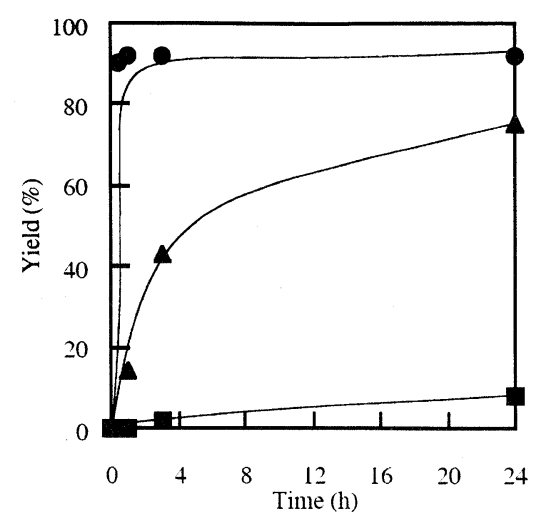

Figure 8. Solvent effect on time-yield profiles in the polymerization of NIPAm. Water (filled circles), methanol (filled triangles) or THF (filled squares) as a solvent $(0.5 \mathrm{M})$.

Second, the virtue of the present method is the ease of anionic end-group transformations. After the initial polymerization of NIPAm using ${ }^{t} \mathrm{Bu}_{4} \mathrm{ZnLi}_{2}$, the resulting terminal zincate of the PNIPAm end can be trapped with an electrophile such as allyl iodide or benzaldehyde to give end-modified new polymers. The end-group modifications were confirmed by the ESI-MS spectra of the obtained polymers, which could be attributed to ${ }^{t} \mathrm{Bu}-(\mathrm{NIPAm})_{\mathrm{n}}-$ allyl $+\mathrm{Na}^{+}$(Figure 9) and ${ }^{t} \mathrm{Bu}-(\mathrm{NIPAm})_{\mathrm{n}}-\mathrm{CH}(\mathrm{OH}) \mathrm{Ph}+\mathrm{Na}^{+}$, respectively.

Third, this method possesses great versatility and high chemoselectivity, and multi-functionalized monomers. This anionic polymerization initiated by ${ }^{t} \mathrm{Bu}_{4} \mathrm{ZnLi}_{2}$ proved to be applicable for the polymerization of $N, N$-dimethylacrylamide (DMA), acrylamide (AM), and 2-hydroxyethyl methacrylate (HEMA). These reactions gave the desired poly(DMA), poly(AM), and poly(HEMA) in 74\%, 84\%, and 92\% yields, respectively.

Finally, in the present ZAP system, the reactivity and selectivity can be tuned via adjustment of several factors of zincates, such as the central metal, the type and number of ligands, and the type of countercations. Therefore, this methodology should have a wide range of applications for highly functionalized macromolecules. Efforts to expand this polymerization scope and to elucidate the reaction pathway with the help of theoretical and spectroscopic studies are in progress in our laboratory. 

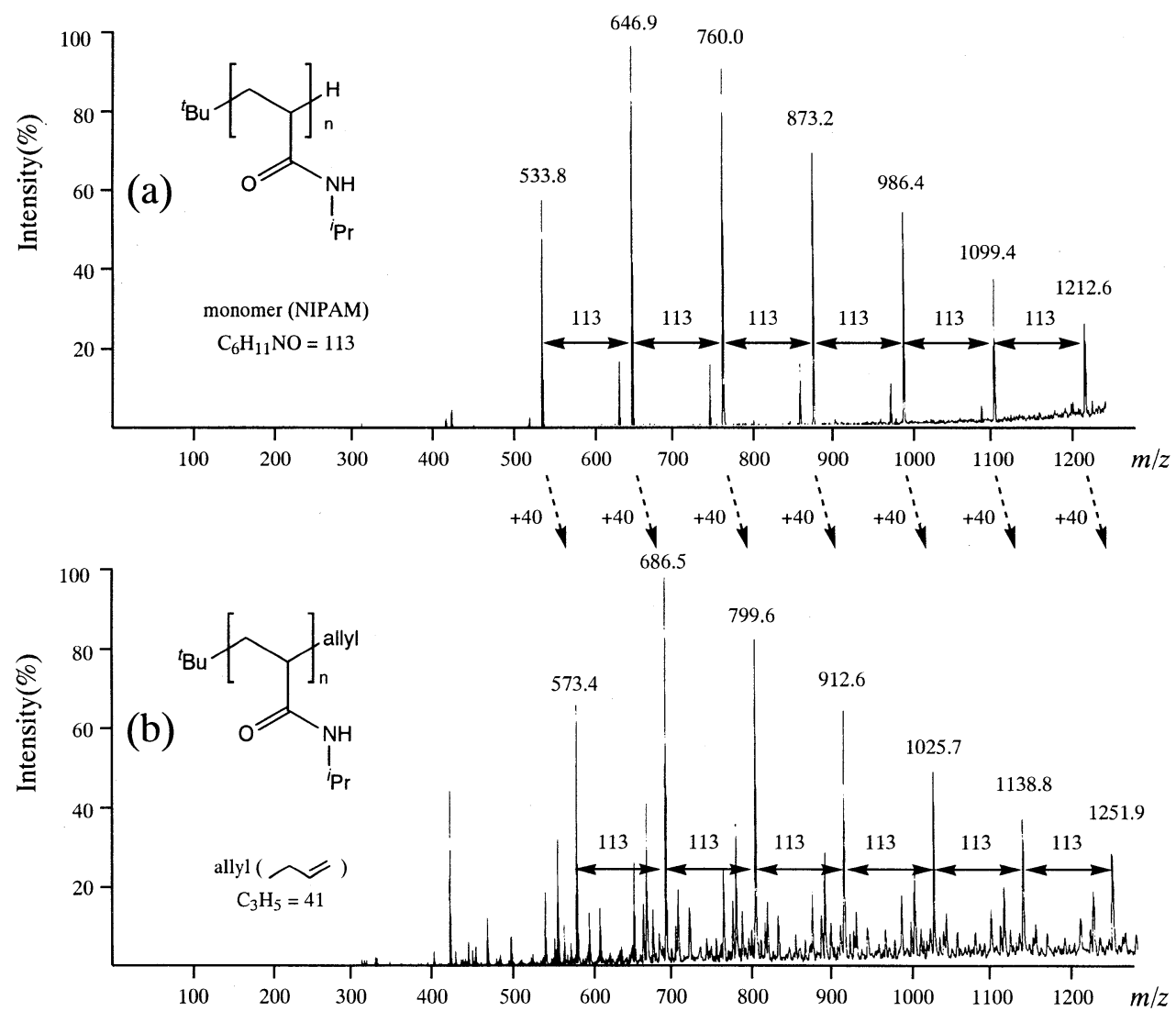

Figure 9. ESI-MS spectra of (a) ${ }^{t} \mathrm{Bu}-(\mathrm{NIPAm})_{\mathrm{n}}-\mathrm{H}$ and (b) the end-allylated poly(NIPAm).

\subsection{Toward a Protecting-Group-Free Halogen-Metal Exchange Reaction Using Dianion-Type Zincate, ${ }^{t} \mathrm{Bu}_{4} \mathbf{Z n L i}_{2}$}

Organometallic reagents so far reported generally have not only halogen-metal exchange ability, but also high nucleophilicity and basicity, and these features have been regarded as difficult or impossible to separate. Thus, the development of a protecting-group-free halogen-metal exchange reaction with high functional group- and acidic proton compatibility remains a tremendous challenge in organic and organometallic chemistry. ${ }^{35}$

In the initial screening of suitable zincates, $p$-iodobenzyl alcohol was selected as a model substrate because it bears an alcoholic proton at the para position to the iodine atom, and this proton is well-known to be involved in protonative quenching of the metalation/C-C bond-forming processes even at extremely low temperature. ${ }^{36}$ After extensive experimentation, we found that ${ }^{t} \mathrm{Bu}_{4} \mathrm{ZnLi}_{2}$ metalated $\mathbf{2 3}$ smoothly at room temperature. The resultant arylzincate was treated with allyl bromide to give $p$-allylbenzyl alcohol in quantitative yield. Stepwise treatments of $\mathbf{2 3}$ with alkyllithiums followed by the addition of zinc reagents were examined, but all were ineffective for the formation of the arylzincates. These observations suggest that the complexation of $\mathrm{Bu}_{2} \mathrm{Zn}$ and 2 $\mathrm{BuLi}$ to form the mixed-metal complex $\mathrm{Bu}_{4} \mathrm{ZnLi}_{2}$ is a prerequisite for successful metalation. Exchange reactions with the use of other zincates, dialkyl zincs or alkyllithiums did not proceed selectively, but instead undesired reactions occurred.

We next confirmed, as shown in Scheme 4, that the arylzincate intermediate (23a) can be utilized as an aryl anion
Scheme 4. Halogen-metal exchange reaction by ${ }^{t} \mathrm{Bu}_{4} \mathrm{ZnLi}_{2}$.

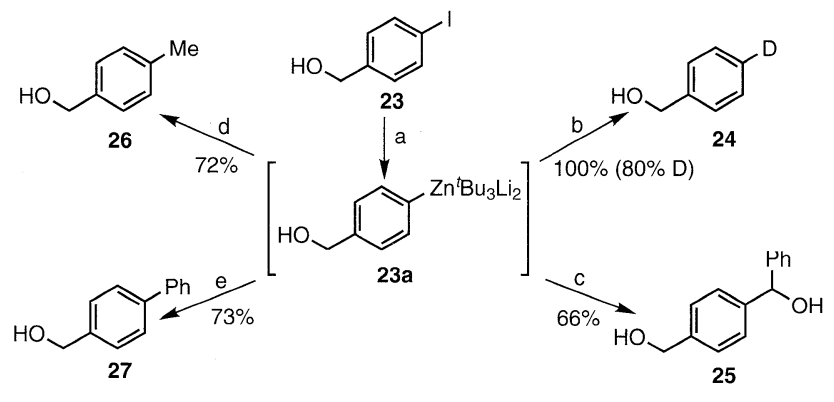

${ }^{a}$ Reagents and conditions: (a) ${ }^{t} \mathrm{Bu}_{4} \mathrm{ZnLi}_{2}$, THF, rt, $2 \mathrm{~h}$; (b) $\mathrm{D}_{2} \mathrm{O}$, rt, $5 \mathrm{~min}$; (c) PhCHO, rt, 12 h; (d) (2-Thienyl)Cu(CN)Li, MeI, rt, $20 \mathrm{~h}$; (e) $2.5 \mathrm{~mol} \% \mathrm{Pd}\left(\mathrm{PPh}_{3}\right)_{4}, \mathrm{PhI}, \mathrm{rt}, 18 \mathrm{~h}$.

equivalent without any protection of the $\mathrm{OH}$ moiety. The intermediate 23a, generated by the exchange reaction of $\mathbf{2 3}$ with ${ }^{t} \mathrm{Bu}_{4} \mathrm{ZnLi}_{2}$, was treated with $\mathrm{D}_{2} \mathrm{O}$ or benzaldehyde to give the corresponding product $\mathbf{2 4}$ or $\mathbf{2 5}$ quantitatively and in $66 \%$ yield, respectively. The intermediate 23a also undergoes copper- and palladium-catalyzed $\mathrm{C}-\mathrm{C}$ bond-forming reactions such as alkylation (26) and phenylation (27) in modest to good yields and with high chemoselectivity. Importantly, extremely low temperature and protection/deprotection processes for the $\mathrm{OH}$ moiety are not required in any of these transformations. Consequently, this represents an exceedingly practical method for chemoselective halogen-metal exchange and is an attractive alternative to the more traditional metalation/ $\mathrm{C}-\mathrm{C}$ bond formation procedures.

The reaction possesses a number of attractive features as a synthetic reaction. For instance, (1) it is compatible with a 
Table 8. Metalation of various functionalized organic halides.

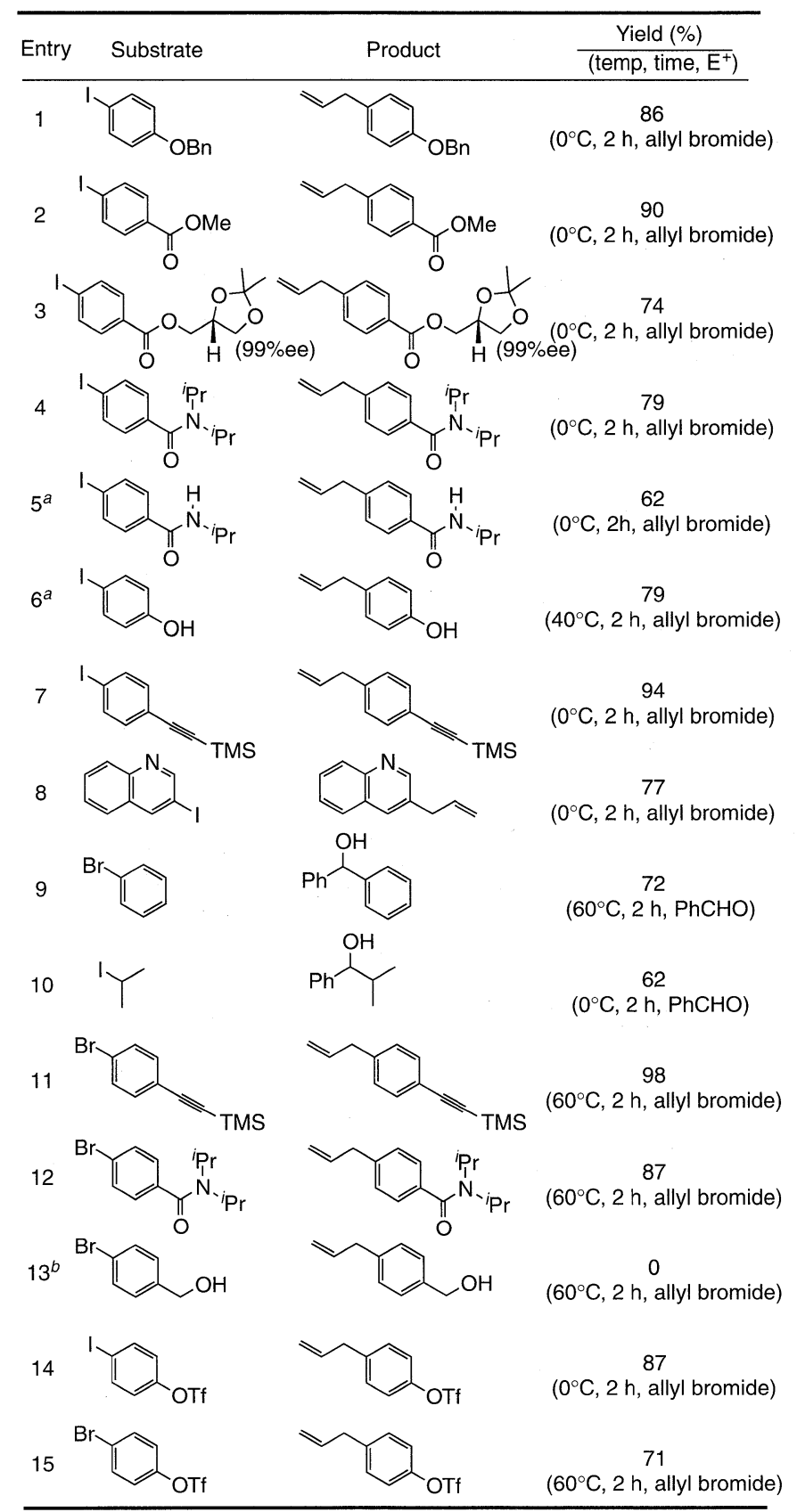

${ }^{a} 2.2$ eq of zincate were used. ${ }^{b}$ Benzyl alcohol was obtained as a major product.

wide variety of functional groups, such as esters, amides, and acidic protons $(\mathrm{C}-\mathrm{H}, \mathrm{N}-\mathrm{H}$ or $\mathrm{O}-\mathrm{H})$ (i.e., protection/deprotection processes for these electrophilic moieties are not required) ${ }^{37}$ (2) various substrates are available, i.e., iodobenzenes, iodoalkanes, and iodoheteroaromatics, and bromobenzenes can also be utilized (3) it proceeds smoothly under mild conditions (extremely low temperature is not required)

\section{Conclusion}

We have developed a new type of zincates, tetra-coordinated dianion-type zincates and breakthrough tools for chemo- and regioselective introduction of various functional groups onto organic molecules by using the chemistry of dianion-type zinc ate complexes. Dianion-type zincates proved to be effective for the chemoselective halogen (or tellurium)-zinc exchange, Michael addition, carbozincation, epoxide ring-opening reactions, silylzincation of terminal alkynes (and alkenes), and anionic polymerizations in aqueous media. On the basis of their excellent chemical yields and chemoselectivities, these species should be differentiated from ordinary triorganozincates, $\mathrm{R}_{3} \mathrm{ZnLi}$. All results based on ${ }^{1} \mathrm{H}$ NMR/Raman/In Situ FTIR/Extended X-ray Absorption Fine Structure (EXAFS) spectroscopic and the density-functional theory (DFT) theoretical studies strongly support the fact that these zincates are a new category of zincate species. We believe the present idea would provide a new way for designing useful organozinc and organometallic reagents for organic synthesis.

\section{Acknowledgements}

The authors thank all the collaborators for their efforts and cooperation, whose names are listed in references cited. This project has been supported by grants from the Japan Society for the Promotion of Science (JSPS), Japan Science and Technology Agency (JST), and the Ministry of Educations, Science, Sports, Culture, and Technology, Japan,

\section{References}

1) (a) Wittig, G. Quart. Revs. 1966, 191. (b) Tochtermann, W. Angew. Chem., Int. Ed. Engl. 1966, 5, 351.

2) (a) Isobe, M.; Kondo, S.; Nagasawa, N.; Goto, T. Chem. Lett. 1977, 679. (b) Tuckmantel, W.; Oshima, K.; Nozaki, H. Chem. Ber. 1986, 119, 1581. (c) Jansen, J. F. G. A.; Ferringa, B. L. Tetrahedron Lett. 1988, 29, 3593. (d) Kjonaas, R. A.; Hoffer, R. K. J. Org. Chem. 1988, 53, 4133.

3) (a) Kondo, Y.; Takazawa, N.; Yamazaki, C.; Sakamoto, T. J. Org. Chem. 1994, 59, 4717. (b) Kondo, Y; Matsudaira, T.; Sato, J; Murata, N.; Sakamoto, T. Angew. Chem., Int. Ed. Engl. 1996, 35, 736. (c) Kondo, Y; Takazawa, N.; Yoshida, A.; Sakamoto, T. J. Chem. Soc., Perkin Trans. 1 1995, 1207. (d) Kondo, Y; Fujinami, M.; Uchiyama, M.; Sakamoto, T. J. Chem. Soc., Perkin Trans. 1 1997, 799.

4) (a) Kondo, Y.; Shilai, M.; Uchiyama, M.; Sakamoto, T. J. Am. Chem. Soc. 1999, 121, 3539. (b) Uchiyama, M.; Miyoshi, T.; Kajihara, Y.; Sakamoto, T.; Otani, Y.; Ohwada, T.; Kondo, Y. J. Am. Chem. Soc. 2002, 124, 8514. (c) Uchiyama, M.; Naka, H.; Matsumoto, Y.; Ohwada, T. J. Am. Chem. Soc. 2004, 126, 10526. (d) Uchiyama, M.; Matsumoto, Y.; Nobuto, D.; Furuyama, T.; Yamaguchi, K.; Morokuma, K. J. Am. Chem. Soc. 2006, 127, 8748. (e) Naka, H.; Uchiyama, M.; Matsumoto, Y; Wheatley, A. E. H.; McPartlin, M.; Morey, J. V.; Kondo, Y. J. Am. Chem. Soc. 2006, in press. (f) Uchiyama, M.; Matsumoto, Y.; Morokuma, K. Angew. Chem. Int. Ed. 2006, in press.

5) (a) Harada, T.; Katsuhira, K.; Hattori, K.; Oku, A. J. Org. Chem. 1993, 58, 2958. (b) Harada, T.; Katsuhira, K.; Hara, D.; Kotani, Y.; Maejima, K.; Kaji, R.; Oku, A. J. Org. Chem. 1993, $58,4897$.

6) Uchiyama, M.; Furumoto, S.; Saito, M.; Kondo, Y.; Sakamoto, T. J. Am. Chem. Soc. 1997, 119, 11425.

7) Uchiyama, M.; Koike, M.; Kameda, M.; Kondo, Y.; Sakamoto, T. J. Am. Chem. Soc. 1996, $118,8733$.

8) (a) Hurd, D. T. J. Org. Chem. 1948, 13, 711. (b) Nast, R. Angew. Chem. 1960, 72, 26. (c) Seitz L. M.; Brown, T. L. J. Am. Chem. Soc. 1966, 88, 4140. (d) Toppet, S.; Slinckx G.; Smets, G. J. Organomet. Chem. 1967, 9, 205. (e) Kaufmann, F.; Geraudelle, A.; Kaempf, B.; Schue, F.; Deluzarche A.; Maillard, A. J. Organomet. Chem. 1974, 71, 11.

9) (a) Weiss, E.; Wolfrum, R. Chem. Ber. 1968, 101, 35. (b) Weiss E.; Plass, H. J. Organomet. Chem. 1968, 14, 21.

10) Weiss, E. Angew. Chem., Int. Ed. Engl. 1993, 32, 1501.

11) Uchiyama, M.; Kondo, Y.; Miura, T.; Sakamoto, T. J. Am. Chem. Soc. 1997, 119, 12372.

12) Book: Gilman, H., Organic Chemistry, John Wiley and Sons, Inc., New York, 1943.

13) Book: Petragnani, N. Tellurium in Organic Synthesis, Academic Press, London, 1994.

14) (a) Hiiro, T.; Morita, Y.; Inoue, T.; Kambe, N.; Ogawa, A.; Ryu, I.; Sonoda, N. J. Am. Chem. Soc. 1990, 112, 455. (b) Tucci, F. C.; Chieffi, A.; Comasseto, J. Tetrahedron Lett. 1992, 33, 5721.

15) (a) Sakamoto, T.; Kondo, Y.; Murata, N.; Yamanaka, H. Tetra- 
hedron Lett., 1992, 33, 5373; (b) Sakamoto, T.; Kondo, Y.; Murata, N.; Yamanaka, H. Tetrahedron, 1993, 49, 971.

16) $n$-Butyl-2-pyridinyltelluride was prepared by nucleophilic substitution reaction of 2-halopyridines with lithium butyltelluroate, see: Kondo, Y.; Shilai, M.; Uchiyama, M.; Sakamoto, T. J. Chem. Soc., Perkin Trans. 1 1996, 1781.

17) (a) Baldwin, J. E. J. Chem. Soc., Chem. Commun. 1976, 734. (b) Johnson, C. D. Acc. Chem. Res. 1993, 26, 476.

18) For discussion on the regioselectivity in the epoxide ring-opening reactions, see: (a) Parham, W. E.; Bradsher, C. K. Acc. Chem. Res. 1982, 15, 300. (b) Brasher, C. K.; Reames, D. C. J. Org. Chem. 1978, 43, 3800. (c) Last, L. A.; Fretz, E. R.; Coates, R. M. J. Org. Chem. 1982, 47, 3211. (d) Cook, Jr., M. P. Houpis, I. N. Tetrahedron Lett. 1985, 26, 3643. (e) Babler, J. H.; Bauta, W.E. Tetrahedron Lett. 1984, 25, 4323. (f) Hardcastle, I. R.; Quale, P.; Ward, E. L. M. Tetrahedron Lett., 1994, 35, 1747. (g) Dhawan, K. L.; Gowland, B. D.; Durst, T. J. Org. Chem. 1980, 45, 924. (h) Rieke, R. D.; Stack, D. E.; Dawson, B. T.; Wu, T.-C. J. Org. Chem. 1993, 58, 2483.

19) Sakamoto, T.; Kondo, Y.; Uchiyama, M.; Yamanaka, H. J. Chem. Soc., Perkin Trans. 1, 1993, 1941

20) (a) Pattenden, G. In Comprehensive Organic Chemistry; Stoddart, J. F., Ed.; Pergamon: Oxford, 1979; Vol. 1, p 171. (b) Denmark, S. E.; Amburgey, J. J. Am. Chem. Soc. 1993, 115, 10386. (c) White, J. D.; Jensen, M. S. Tetrahedron 1995, 51, 5743. (d) Creton, I.; Marek, I.; Normant, J. F. Synthesis 1996, 1499. (e) Brown, S. D.; Armstrong, R. W. J. Am. Chem. Soc. 1996, 118, 6331. (f) Organ, M. G.; Cooper, J. T.; Rogers, L. R.; Soleymanzadeh, F.; Paul, T. J. Org. Chem. 2000, 65, 7959.

21) (a) (Si-Al) Hayami, H.; Sato, M.; Kanemoto, S.; Morizawa, Y.; Oshima, K.; Nozaki, H. J . Am. Chem. Soc. 1983, 105, 4491. (b) (Si-B) Silva, J. C. A. D.; Birot, M.; Pillot, J.-P.; Petraud, M. J. Organomet. Chem. 2002, 646, 179. (c) (Si-Zn) Okuda, Y.; Wakamatsu, K.; Tuckmantel, W.; Oshima, K.; Nozaki, H. Tetrahedron Lett. 1985, 26, 4629. (d) (Si-Zn) Wakamatsu, K.; Nonaka, T.; Okuda, Y.; Tuckmantel, W.; Oshima, K.; Utimoto, K.; Nozaki, H. Tetrahedron 1986, 42, 4427.

22) Nakamura, S.; Uchiyama, S.; Ohwada, T. J. Am. Chem. Soc. 2004, 126, 11146

23) For recent reviews on allylmetal chemistry see: (a) Denmark, S E.; Almstead, N. G. In Modern Carbonyl Chemistry; Otera, J., Ed.; Wiley-VCH: Weinheim, 2000; Chapter 10. (b) Stereoselective Synthesis, Methods of Organic Chemistry (Houben-Weyl), E2I ed.; Helmchen, G., Hoffmann, R., Mulzer, J., Schaumann, E., Eds.; Thieme: Stuttgart, 1996; Vol. 3, p 1357. (c) Krause, N. Modern Organocopper Chemistry; Wiley-VCH: Weinheim, 2002.

24) For reviews on synthesis of allylsilanes see: (a) Barbero, A.; Pulido, F. J. Acc. Chem. Res. 2004, 37, 817. (b) Fleming, I. Science of Synthesis: HoubenWeyl Methods of Molecular Transformations: Thieme Stuttgart, 2001, Vol. 4, Ed. (c) Sarkar, T. K. Syrthesis, 1990, 969. (d) Sarkar, T. K. Synthesis, 1990, 1101. See also: (d) Barbero, A.; Castreño, P.; Pulido, F. J. J. Am. Chem. Soc. 2005, 127, 8022. (e) Barbero, A.; Castreño, P.; Pulido, F. $J$ Org. Lett. 2003, 5, 4045. (f) Liepins, V.; Karlstrom, S. E.; Backvall, J.-E. Org. Lett. 2000, 2, 1237. (g) Blanco, F. J.; Cuadrado, P.; Gonzalez, A. M.; Pulido, F. J.; Fleming, I. Tetrahedron Lett. 1994, 35, 8881.

25) Nakamura, S.; Uchiyama, M.; Ohwada, T. J. Am. Chem. Soc. 2005, 127, 13116

26) (a) Seki, Y.; Takeshita, K.; Kawamoto, K.; Murai, S.; Sonoda, N. J. Org. Chem. 1986, 51, 3890. (b) Hori, Y.; Mitsudo, T.; Watanabe, Y. Bull. Chem. Soc. Jpn. 1988, 61, 3011.

27) (a) Lagowski, J. J. Polymer Chemistry; Marcel Dekker: New York, 1988. (b) Nakahama, S.; Hirao, A. Prog. Polym. Sci. 1990, 15, 299. (c) Davis, T. P.; Haddleton, D. M.; Richards, S. N. J. Macromol. Sci., Rev. Macromol. Chem. Phys. 1994, C34, 243.

28) Hsieh, H. L.; Quirk, R. P. Anionic Polymerization; Marcel Dekker: New York, 1996

29) Goode, W. E.; Owens, F. H.; Fellmann, R. P.; Snyder, W. H. J. Polym. Sci. 1960, 46, 317.

30) Shibayama, M.; Tanaka, T. Volume Phase Transition and Related Phenomena of Polymer Gels; Springer-Verlag: Berlin, 1993.

31) (a) Bergbreiter, D. E.; Caraway, J. W. J. Am. Chem. Soc. 1996, 118, 6092. (b) Bergbreiter, D. E.; Liu, Y.-S.; Osburn, P. L.J. Am. Chem. Soc. 1998, 120, 4250. (c) Bergbreiter, D. E. Chem. Rev. 2002, 102, 3345.

32) Ding, Z. L.; Fong, R. B.; Long, C. J.; Stayton, P. S.; Hoffman, A. S. Nature 2001, 411, 59.

33) (a) Iwataki, T.; Yoshikawa, K.; Kidoaki, S.; Umeno, D.; Kiji,
M.; Maeda, M. J. Am. Chem. Soc. 2000, 122, 9891. (b) Arotcarena, M.; Heise, B.; Ishaya, S.; Laschewsky, A. J. Am. Chem. Soc. 2002, 124, 3787. (c) Kikuchi, A.; Okano, T. Prog. Polym. Sci. 2002, 27, 1165 .

34) PNIPAm has been synthesized by anionic polymerization using $\mathrm{N}$-protected monomers, for example; Ishizone, T.; Ito, M. $J$. Polym. Sci., Part A: Polym. Chem. 2002, 40, 4328.

35) Increasing attention has been devoted to the protecting-groupfree synthesis driven by the development of powerful and chemoselective transformations. For example, see: (a) Baran, P. S.; Richter, J. M. J. Am. Chem. Soc., 2005, 127, 15394. (b) Kopp, F.; Krasovskiy, A.; Knochel, P. Chem. Commun. 2004, 2288. (c) Jackson, R. F. W.; Rilatt, I.; Murray, P. J. Org. Biomol. Chem., 2004, 2, 110 .

36) (a) Beak, P.; Musick, T. J.; Chen, C. W. J. Am. Chem. Soc., 1988, 110, 3538. (b) Gallagher, D. J.; Beak, P. J. Am. Chem. Soc.; 1991; $113 ; 7984$.

37) The $\mathrm{C}-\mathrm{C}$ bond-forming reaction with the use of other zincates or alkyllithiums did not proceed under the same reaction conditions, but instead undesired reactions occurred.

\section{PROFILE}

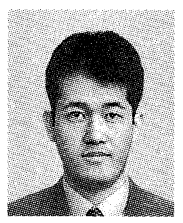

Masanobu Uchiyama is Associate Chief Scientist, Director of Advanced Elements Chemistry Laboratory at RIKEN. He received his B. Sc. (1993) from Tohoku University and M. Sc. (1995) from The University of Tokyo. He was appointed an assistant professor (1995) at Tohoku University and then received his $\mathrm{Ph}$. D. degree (1998) from The University of Tokyo. He moved to the Graduate School of Pharmaceutical Sciences, The University of Tokyo, as an assistant professor in 2001 and was promoted to Lecturer in 2003. In 2004 and 2005, he worked as a visiting scientist with Prof. Keiji Morokuma at Emory University. He has been now Associate Chief Scientist of The Institute of Physical and Chemical Research at RIKEN since 2006. From 2001-2004, he served concurrently on a 3-year project of "Synthesis and Control", PRESTO, Japan Science and Technology Agency (JST). He received the Banyu Young Chemist Award (1999), The Pharmaceutical Society of Japan Award for Young Scientists (2001) and Inoue Research Award for Young Scientists (2002). His research interests are in the area of synthetic organic chemistry based on organometallic chemistry, physical chemistry, and computational chemistry.

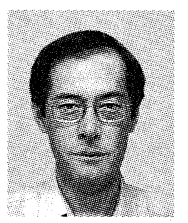

Yoshinori Kondo is Professor of Graduate School of Pharmaceutical Sciences, Tohoku University. He received his B. Sc. (1980) and M. Sc. (1982) from Tohoku University. He was appointed an assistant professor (1983) and received his $\mathrm{Ph}$. D. degree in 1987 from Tohoku University. From 1989 to 1990 , he worked as a visiting scholar in Professor Trost's group at Stanford University. He was promoted to Associate Professor in 1994 and has been Professor since 1999 . His research interests include synthetic organic chemistry, organometallic chemistry, heterocyclic chemistry. He is a recipient of the Miyata Prize (2001). 